Ekanem et al., Afr J Tradit Complement Altern Med., (2018) 15 (3): 31-37

https://doi.org/10.21010/ajtcam.v15i3.4

\title{
EFFECT OF CONSUMPTION OF HIBISCUS SABDARIFFA AND AZADIRACHTA INIDCA PRENATALLY AND POSTNATALLY ON MILK CREAMATOCRIT AND EARLY GROWTH OF OFFSPRING
}

\section{Ekanem E. Ephraim ${ }^{1,2}$, Ituen Aniema ${ }^{2}$, Ezeh O. Charles, ${ }^{1,3}$ Okorie Pamela $^{2}$, Uzoigwe Jide ${ }^{2}$, Ugwu Princewill ${ }^{2}$, Iyare E. Eghosa, ${ }^{1,2^{*}}$}

${ }^{1}$ Reproductive and Developmental Programming Research Group, Department of Physiology, College of Medicine, University of Nigeria, Enugu Campus, Nigeria. ${ }^{2}$ Department of Physiology, College of Medicine, University of Nigeria, Enugu Campus, Nigeria. ${ }^{3}$ Department of Medical Biochemistry, College of Medicine, University of Nigeria, Enugu Campus, Nigeria.

*Corresponding Author E-mail: eghosa.iyare@unn.edu.ng

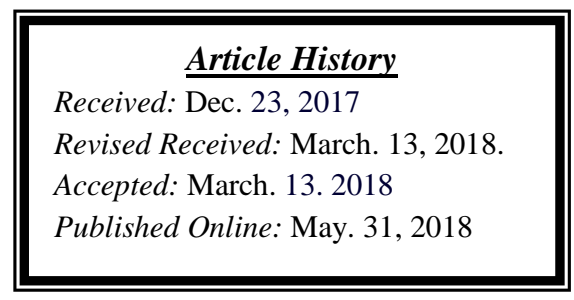

\begin{abstract}
Background: Aqueous extracts of Hibiscus sabdariffa Linn. (HS) and Azadirachta indica A. juss (AI) are widely used in Nigeria for medicinal purposes and have been shown to affect postnatal growth of offspring. Breast milk creamatocrit is a simple accurate inexpensive technique and useful measure of lipid and energy content of breast milk. No data has shown effects of these extracts on breast milk creamatocrit and early postnatal growth of offspring. This study was designed to investigate effects of HS and AI on breast milk creamatocrit and early postnatal growth of offspring.

Materials and Methods: 40 pregnant rats weighing 150-200g were used for this study. They were divided into control, HS and AI groups. These groups were subdivided into two of low and high doses. Administration was by gavage and commenced on day 1 of pregnancy and ended on postnatal day 21. Litter weight and length were recorded at birth, postnatal days 7-21. Breast milk was collected from 4 dams in each group at postnatal days 7-21 for milk creamatocrit. Results: Results showed that aqueous extract of HS and AI caused progressive increase in milk creamatocrit during lactation. This increase peaked greatly in the third week of lactation. There was also a progressive increase in BMI of pups in extract treated group that became significantly greater at weaning.

Conclusion: In conclusion, consumption of aqueous extracts of HS and AI during pregnancy and lactation may accelerate the postnatal growth of the offspring through mechanisms that may depend on increased breast milk creamatocrit.
\end{abstract}

Keywords: Hibiscus sabdariffa, Azadirachta indica, Breast milk creamatocrit, early postnatal growth

\section{Introduction}

Medicinal plants over the years have been part and parcel of human society for the combat of diseases. These plants have been reliable sources of food because they provide essential nutritional values, medicinal properties and notable physiological effect to life (Dalziel, 1973).

Hibiscus Sabdariffa Linn (HS) and Azadinachta indica A. juss (AI) are used as medicinal and food ingredients in many parts of the world including Nigeria. Both plants are highly sourced as food vegetable particularly because of their health promoting and diseases-preventing properties strongly suspected to be due to the presence of many phytochemicals in them (Ijeomah et al, 2012). These phytochemicals in the two plants have been found to be protective and preventive against many degenerative diseases and pathological process such as in ageing (Burns et al., 2001).

HS (family: Malvaceae) commonly known as zobo in Nigeria, is an annual herbaceous shrub, cultivated for its flowers, leaves and seeds. It is found in the tropics, subtropics and other parts of the world (Dalziel, 1973) but it is utilized beyond these areas of cultivation globally. In folk medicine this medicinal herb is used for the treatment of hypertension (Wang et al., 2000; Odigie et al., 2003). The plant is also reported to have hepatoprotective, antihyperlipidemic, anticancer and antioxidant properties (Mahadevan and Shivali-kamboj, 2009). 
AI (family: Meliaceae), commonly referred to as Dogonyaro or neem plant is an evergreen robust tree. It is mostly found in tropic and sub- tropical areas of the world, African and Asia (Ejoba, 2012). The tree occurs in medium to large size and has dark grey bark and a dense rounded row of pinnate leaves (Ogbuewu, 2008). All parts of the neem tree (leaves, flowers, seeds, fruits, roots and bark) are widely used in traditional medicine. AI is used for the treatment of many health-related problems and known to exert anticancer, antioxidant, wound-healing and antimicrobial properties. All parts of this plant are useful and has been used to treat diseases ranging from tooth decay, ulcer, swollen liver, malaria and dysentery (Ogbuewu, 2008; Mossini et al., 2004).

Breast milk is the normative standard for infant feeding and nutrition because it has been associated with a reduction in the incidence of gastrointestinal tract infection, respiratory tract infection and otitis media (American Association of Paediatrics, 2012; World Health Oranization, 2013). It is important to note that breast milk is widely accepted to be the optimal source of nutrition for the newborn infants because it contains appropriate amount of protein, lipid, carbohydrate, micronutrients, trace elements, vitamins, minerals, digestive enzyme and hormones required for early postnatal growth of offspring, development and immune protection. However, it is now universally recognized that there is no commercial formula that can equal breast milk. The relationship of breast milk feeding with a significant reduction in the incidence of necrotizing enterocolitis (NEC) has been suggested in preterm infants (Sullivan, 2010). Additionally, there is extensive evidence that offspring who had been breastfed with breast milk show lower risk of same non-communicable diseases later in life (American Association of Paediatrics, 2012; World Health Oranization, 2013). Indeed, breast milk given to infant at the early postnatal stage has been associated with lower risk of obesity, lower levels of arterial blood pressure, lower total and LDL-blood cholesterol level in adulthood and lower risk of developing type-2 diabetes (American Association of Paediatrics, 2012; World Health Oranization, 2013). Breast milk is not only associated with improved parameters of growth in offspring but also with a better neuronalbehavioral development (Mortensen et al., 2002; American Association of Paediatrics, 2012). Breast milk creamatocrit is the cream column separated from the milk by centrifugation and expressed as a percentage of the length of the total milk column. It is a simple method of estimating the calorific value of breast milk (Lucas, 1978).

Infant growth during the early postnatal period is obviously the result of the development of complex functional, structural and metabolic mechanisms, which are however not yet entirely clarified (Patel and Srinivasan, 2010). However, this period is characterized by a great plasticity with critical windows in which any inadequate insult or intervention may cause both positive and adverse postnatal growth and development (Ostadalova and Babicky, 2012). The present study was thus designed to determine the effect of consumption of aqueous extract of HS and AI during pregnancy and lactation on breast milk creamatocrit and early postnatal growth of offspring.

\section{Materials and Method \\ Plant Collection, Identifcation and Extract Preparation}

Matured calyces of HS were purchased from a local market in Enugu and fresh matured leaves from AI tree located in the premises of University of Nigeria, Enugu campus were harvested. Both plant samples were identified and authenticated by Mr. Onyeukwu, C.J. of the Department of Plant Science and Biotechnology, University of Nigeria, Nsukka where voucher specimens (numbers UNH No $75 \mathrm{f}$ and UNH No. $521^{\mathrm{A}}$ respectively) were deposited.

The extraction procedure used for HS was as described previously (Iyare and Adegoke, 2011). Briefly, 300g of the dry calyces of HS was brewed in $4000 \mathrm{ml}$ of boiled tap water for $45 \mathrm{~min}$. The resulting decoction was filtered and evaporated to dryness giving a dark red paste with percentage extraction yield of $47 \%$. The leaves of AI were washed and air-dried. The dried leaves were homogenized using an electric blender. The powder was exhaustively extracted in distilled water at $60^{\circ} \mathrm{c}$ for 48 hours using soxhlet extractor according to a previously described method (Biu et al., 2010). The resulting decoction was also filtered and evaporated to dryness giving a black paste with percentage extraction yield of $19.5 \%$. Both extracts were stored in the refrigerator for preservation until use.

\section{Phytochemical analysis}

The standard method of Trease and Evans (2002) were used in the analysis of the phytochemcal components of calyces of HS and leaves of AI. The qualitative and quantitative phytochemical analyses of the extracts are presented in Table 1.

\section{Experimental animals}

40 inbred virgin albino rats aged between 10-12 weeks weighing 150-200g with two consecutive regular 4day estrus cycles were used for this study. The rats were housed in cages and acclimatized for 2 weeks and maintained under standard environmental conditions and were also allowed free access to food (grower pelleted feed) and water. 10 male rats of proven fertility were introduced into the cages in the ratio of 1: 4 to allow for mating. Day 1 of pregnancy was taken as the day sperm was seen in the vaginal smear of the rats (Benie et al., 2003). 
On day 1 of pregnancy the rats were randomly divided into 3 groups: $\mathrm{A}, \mathrm{B}$ and $\mathrm{C}$ with groups $\mathrm{A}$ and $\mathrm{B}$ further subdivided into two subgroups of low and high doses. Extract administration also commenced on day 1 of pregnancy and ended on postpartum day 21.

Group A $(\mathbf{n}=16)$ : This group was administered HS extract in two doses: low dose $(1.5 \mathrm{~g} / \mathrm{Kg}$ body weight $)$ and high dose ( $3 \mathrm{~g} / \mathrm{Kg}$ body weight) (Iyare and Adegoke, 2008).

Group B $(\mathbf{n = 1 6})$ : This group was administered AI in two doses also: low dose (200mg/Kg body weight) and high dose (400mg/Kg body weight) (Iyare and Obaji, 2014).

Group $\mathbf{C}(\mathbf{n}=\mathbf{8})$ : This group was the control group and was administered water.

This work was approved by the Research and Ethics Committee of the Directorate of Research and Publications, College of Medicine, University of Nigeria, Enugu Campus, Enugu with protocol number 040/02/2016. Approval date was 28/02/2016.

\section{Measurement of litter size, length and weight}

On the day of delivery, litter sizes, lengths and weights were recorded using a stainless metre rule (WINS FISH BRAND, CHINA) and a digital electronic compact balance (S. METTLER, CHINA). Litter weights and length were subsequently recorded at postnatal days 7, 14 and 21.

\section{Breast milk collection and creamatocrit determination}

Breast milk was collected from 4 dams in each subgroup at postnatal days 7, 14 and 21 according to the method of Paul et al., (2015) but with slight modification. On each day, dams were separated from their pups for 3 hours prior to milking to allow accumulation of the breast milk. Subsequently the dams were injected with $0.1 \mathrm{ml}$ of oxytocin (10iu/ml, oxytocin Bengen, WdT eG, Garbsen, Germany) intraperitoneally and after 1 minute the milking process commenced. The mammary glands of the dams were massaged slightly to induce milk ejection reflex. The dams were milked by gently applying pressure to the base of the mammary gland until milk became visible. All teats of each dam were repeatedly milked for a period of 10 to $15 \mathrm{~min}$. The milk was collected in a plain sample container. Milk volume collected ranged between $0.4 \mathrm{ml}-0.5 \mathrm{ml}$ per dam. The expressed breast milk was collected from the sample container into an 80iu/ml non- heparinized micro haematocrit tube (Vasekaer 6-8 dk-2730 Harlev, Denmark) through capillary action. The haematocrit tube was immediately placed in a haematocrit machine (Hawksley England) and Centrifuged at $3000 \mathrm{rpm}$ for $15 \mathrm{~min}$ until the lipid or cream part separated from the aqueous part of the milk. After centrifugation the haematocrit tube was placed vertically on an heamatocrit reader (Hawksley England) and the length of the packed cream layer at the top of the tube was read directly within one hour. The cream layer was expressed as percentage of milk column to indicate the creamatocrit value (Chatterjee et al., 1986; Du et al., 2017).

\section{Statistical analysis}

The data were analyzed statistically using SPSS version 20.0. Results were expressed as mean \pm standard error of means (SEM) and an analysis of variance followed by a post-hoc Student-Neuman-Keuls' test. $\mathrm{P}<0.05$ was considered statistically significant.

\section{Results}

Table 1: The phytochemical analyses of the aqueous extracts of Hibiscus sabdariffa calyces and Azadirachta indica leaves

\begin{tabular}{|c|c|c|c|c|c|}
\hline \multirow[b]{2}{*}{ Constituents } & \multirow[b]{2}{*}{ Units } & \multicolumn{2}{|c|}{ Hibiscus sabdariffa } & \multicolumn{2}{|c|}{ Azadirachta indica } \\
\hline & & Qualitative & Quantitative & Qualitative & Quantitative \\
\hline Alkaloid & $\%$ & + & 0.105 & ++ & 0.13 \\
\hline Saponin & $\%$ & ++ & 1.083 & ++ & 0.297 \\
\hline Flavonoid & $\%$ & ++ & 26.256 & + & 7.289 \\
\hline Tannin & $\%$ & & & ++ & 1.625 \\
\hline Steroid & $\mathrm{mg} / \mathrm{ml}$ & ++ & 0.3113 & & \\
\hline Glycoside & $\mathrm{mg} / \mathrm{ml}$ & ++ & 1.564 & & \\
\hline Reducing sugar & $\mathrm{mg} / \mathrm{ml}$ & + & 17.5 & & \\
\hline Phenol & $\mathrm{mg} / \mathrm{ml}$ & & & + & 8.748 \\
\hline
\end{tabular}

$+=$ Slight $;++=$ Moderate 
Result showed a progressive increase in breast milk creamatocrit value that peaked in the third week of lactation in both extract groups when compared with control except low dose HS that was lowest in the $3^{\text {rd }}$ week (Table 2).

Table 2: Effect of consumption of aqueous extract of Hibiscus sabdariffa and Azadirachta indica on breast milk creamatocrit value

\begin{tabular}{lccccccc}
\hline & \multicolumn{3}{c}{ Hibiscus sabdariffa } & \multicolumn{2}{c}{ Azadirachta indica } \\
Periods & Control & Low Dose & High Dose & Control & Low Dose & High Dose \\
\hline $1^{\text {st }}$ week & $27.50 \pm 0.35$ & $34.50 \pm 0.35^{*}$ & $25.19 \pm 1.30$ & & $27.50 \pm 0.35$ & $31.00 \pm 0.71^{*}$ & $35.50 \pm 0.35^{*}$ \\
$2^{\text {nd }}$ week & $28.50 \pm 0.35$ & $36.00 \pm 0.00^{*}$ & $35.50 \pm 0.35^{*}$ & & $28.50 \pm 0.35$ & $33.00 \pm 0.71 *$ & $30.00 \pm 0.00^{*}$ \\
$3^{\text {rd }}$ week & $32.00 \pm 0.71$ & $26.50 \pm 0.35^{*}$ & $35.00 \pm 0.00^{*}$ & & $32.00 \pm 0.71$ & $38.50 \pm 0.35^{*}$ & $44.50 \pm 0.35^{*}$ \\
\hline
\end{tabular}

$*^{*}=\mathrm{p}<0.05$ vs control; Low dose HS (1.5g/kg bwt) and high dose HS (3.0g/kg bwt); Low dose AI (200mg/kg bwt) and high dose AI (400mg/kg bwt)

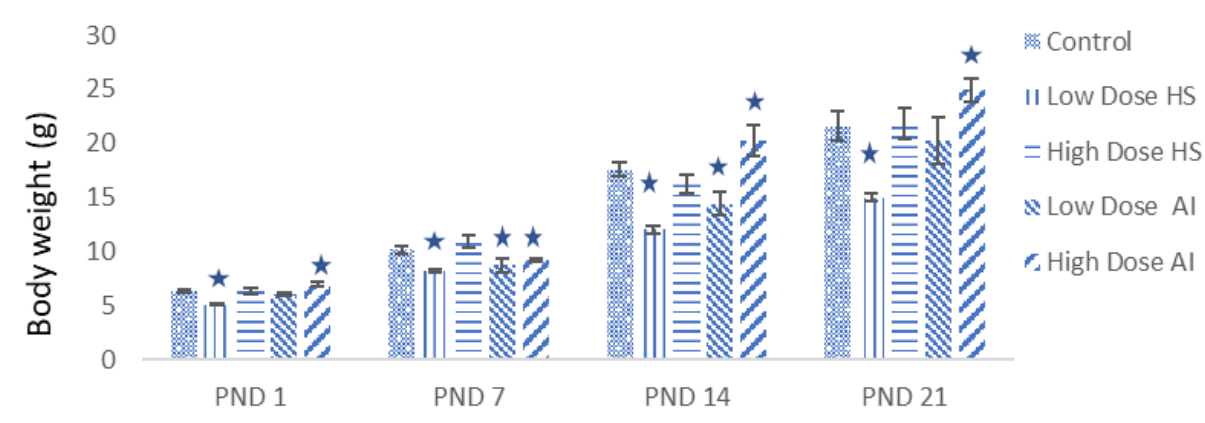

Fig. 1: Effect of consumption of aqueous extracts of Hibiscus sabdriffa and Azadirachta indica during pregnancy and lactation on postnatal weight of the offspring.

$\mathrm{PND}=$ Postnatal Day; ${ }^{\star}=\mathrm{P}<0.05$ vs Control

Figure 1: Effect of consumption of aqueous extract of Hibiscus sabdariffa during pregnancy and lactation on body weight of offspring

Result showed that the body weights of the low dose HS groups were consistently lower from birth to day 21 compared with both control and high dose groups whereas the body weights of the high dose group were consistently similar with those of the control groups from birth to day 21. For the AI, result showed a consistent decrease in body weight in low dose AI group compared with control except at birth and day 21 were they were similar. That of the high dose showed a consistent increase except at day 7 when it was significantly lower than that of the control. 


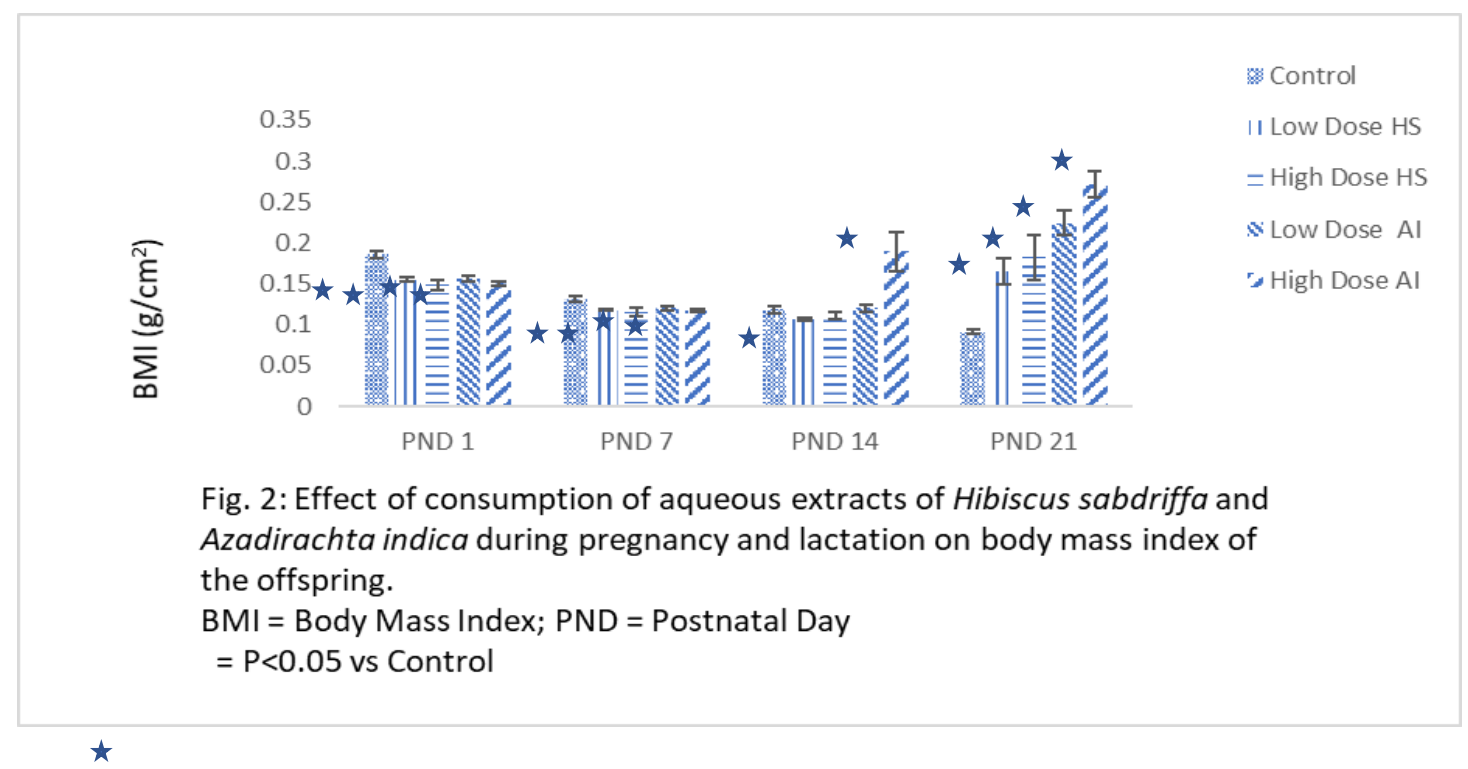

Figure 2: Effect of consumption of aqueous extract of Hibiscus sabdariffa and Azadirachta indica during pregnancy and lactation on BMI of offspring

Result showed a significant increase in BMI of the control offspring at birth and at day 7 relative to the low and high dose HS extract groups. At day 14, there appeared a reversal of trend as there was no difference in the BMI between the control group and the high dose HS group. Only the BMI of the low dose group was significantly lower. At day 21, the BMI of both low and high dose HS groups were significantly higher than that of the control group. Result also showed a similar trend in BMI for the AI groups as observed for HS. There was also an observed decrease in BMI in the low and high dose groups of AI at birth and day 7. But on day 14, the low dose AI levelled up and became similar with that of the control while the high dose was increased. At day 21, however, the BMI of both low and high dose AI were significantly higher than that of the control.

\section{Discussion}

\section{Breast milk creamatocrit}

An important variable in the study of breast milk is the lipid concentration which is the major determinant of the energy value because lipids are essential for the formation of cell membranes, hormones and are necessary for proper eye and brain development especially during prenatal period and into the first few years of the child life (Innis and Friesen, 2008). Breast milk creamatocrit is the cream column separated from the milk by centrifugation and expressed as a percentage of the length of the total milk column (Vasquez-Roman et al., 2014). It is a simple method of estimating the calorific value of breast milk (Lucas, 1978; Wang et al., 2000). Although the gravimetric method is the gold standard for determining the fat content of breast milk, the creamatocrit method is preferable because of the ease of operation and real-time analysis (Du et al., 2017). Herbs and plants have been reported to have lactogenic effect (Goyal et al., 2003; Ouedraogo et al., 2004). There have been reports that some African women with lactation insufficiency particularly those living in villages depend largely on herbal supplements for milk increase or milk induction despite the modern alternative of bottle/formula feeding (Okasha et al., 2008).

Both extracts of HS and AI are rich in glycoside, saponin, steroid, flavonoid and tannin as shown in table 4.2.1 and 4.2.2. These components have been shown to increase breast milk yield (Okasha et al., 2008; Bako et al., 2013). It is possible therefore that these components in the extracts may have been responsible for the observed increase breast milk creamatocrit in the present study.

\section{Postnatal growth}

The present study showed a significant increase in BMI of the control offspring at birth relative to the HS and AI extract group which. This observation is instructive because anecdotal reports by women who consume these extracts suggest that they do so because of the folkloric belief that these extracts make delivery easy. This observed increase in BMI of the control showed a progressive decrease as lactation progressed until PND 14 of lactation when there appeared a reversal of trend. At PND 14, only the BMI of the low dose HS was significantly lower whereas low dose AI and high dose HS were not significantly different and the high dose AI was significantly higher. Beyond PND 14 there appeared a progressive increase in the BMI of HS and AI extract treated group relative to control. This increase appeared to peak at PND 21. Since the infant is not fully matured at birth and since the process of maturation 
continues during the immediate postnatal period (Patel and Srinivasan, 2010), the importance of breastmilk becomes very significant at this period since it is the only source of nutrition for the maturing pups. Larger milk volume and greater energy intake especially from the higher milk fat content from the early days of lactation results in a faster growth in pups. These suggest that the observed effects on the postnatal growth of offspring in this study may be linked to the extract-induced increase in breast milk creamatocrit and by extension, increased fat and energy content. Increased creamatocrit value is an index of increased lipid concentration and increased lipid is rich in calories which is a vital tool for the early postnatal growth and development of offspring.

\section{Conclusion}

From the results of the present study, it can be concluded that consumption of aqueous extracts of HS and AI during pregnancy and lactation may accelerate the postnatal growth of the offspring possibly through increased breast milk creamatocrit. Further work needs to be done to ascertain the volume of breast milk consumed by the pups so as to be able to definitively link the accelerated growth with the volume of milk consumed.

Acknowledgement: This work was supported in part by African Research League.

Conflict of Interest: We have no conflict of interest to disclose.

\section{References}

1. American Academy of Pediatrics. (2012). Breastfeeding and the Use of Human Milk, Pediatrics. 29: e827-e841.

2. Bako, I.G., Mabronk, M.A., Abubakar, M.S and Mohammed, A. (2013). Lactogenic Study of the Ethyl-Acetate Fraction of Hibiscus Sabdariffa Linn Seed on Pituitary Prolactin Level of Lactating Albino Rats. International Journal of Applied Research in Natural Products (IJARNP). 6 (2): 30-37.

3. Benie, T., Duval, J. and Thieulant, M.L. (2003). Effect of some Traditional Plant Extracts on Rat Oestrus Cycle Compared with Clomid. Phytotherapy Research. 17:748-751.

4. Biu, A. A., Yusufu, S.D. and Rabo, J.S. (2010). Acute toxicity study on neem (Azadirachta indica, juss) leaf aqueous extract in chicken (Gallus gallu domestius). African scientist. 11(4): 241-244.

5. Burns, J.P.T, Gardner, D., Mathew, G.G, Duthie, M., Lean, E and Crozier, A. (2001). Extraction of Phenolic and Changes in Antioxidant Activity of Red Wine During vinification, Journal of Agriculture and Food Chemistry. 49: 5797-5808.

6. Chatterjee, R., Chatterjee, S. and Datta, T. (1986), Caloric value of Breast Milk. Indian Pediatric. 23: $921-924$.

7. Dalziel, T.M. (1973). The useful plant of tropical Africa 3rd edition, London: Watmought ltd, Bradford, pp.526530 .

8. Du, J., Gay, M.C.L., Lai, C.T. Trengove, R.D., Hartmann, P.E. and Geddes, D.T. (2017). Comparison of gravimetic, creamatocrit and esterified fatty acid methods for determination of total fat content in human milk. Food Chemistry. 217: 505-510.

9. Ejoba, R. (2012). Phytochemical Constituents of Some Leaves Extract of aloe Vera and Azadirachta indica Plant Species. Global Advanced Research Journal of Environmental Science and Toxicology. 1 (2): 014-017.

10. Goyal, R.K., Singh, J. and Harbans, L. (2003). Asparagus recemosus an update review indicant. Journal of Medical Sciences. 57(9): 408- 414.

11. Ijeomah, A.U., Ugwuona, F.U. and Abdullahi, H. (2012). Phytochemical Composition and Antioxidant Properties of Hibiscus sabdariffa and Moringa oleifera. Nigeria Journal of Agriculture Food and Environment. 8(1): 10-16.

12. Innis, S.M. and Friesen, R. W. (2008). Essential n-3 fatty acids in pregnant women and early visual acuity maturation in term infants. American Journal of Clinical Nutrition. 87 (3): 548-557.

13. Iyare, E.E. and Adegoke, O.A. (2008). Body mass index at onset of puberty in rats exposed to aqueous extract of Hibiscus sabdariffa in utero. African Journal of Biomedical Research. 11: 203-208.

14. lyare, E.E. and Adegoke, O.A. (2011). Gestational Outcome in Rats that Consumed Aqueous Extract of Hibiscus Sabdariffa during Pregnancy. Pakistan Journal of Nutrition. 10(4): 350 - 354.

15. Iyare, E.E., and Obaji, N. N. (2014). Effects of aqueous leaf extract of Azadirachta indica on some haematological parameters and blood glucose level in female rats. Nigerian Journal of Experimental and Clinical Biosciences. 2 (1): 54-58.

16. Lucas, A., Gibbs, J.A.H., Lyster, R.L.J. and Baum, J.D. (1978). Creamatocrit: Simple Clinical Technique for Estimating Fat Concentration and Energy Value of Human Milk. British Medical Journal. 1: 1018-1023.

17. Mahadevan, N. and Shivali Kamboj, P. (2009). Hibiscus Sabdariffa Linn -An Overview. Indian Journal of Natural Products and Resources (IJNPR). 8(1): 77-83.

18. Mortensen, E.L., Michaelsen, K.F., Sanders, S. A. and Reimisch, J.M. (2002). The Association Between Duration of Breastfeeding and Adult Intelligence. Journal of American Medical Association. 287: 2365-2371. 
19. Mossini, S.A., Oliveira, K.P. and Kemmelmeier, C. (2004). Inhibition of Patulin Production by Penicullium Expansium Culture with Neem (Azadirachta indica) Leaf Extracts. Basic Microbiology. 44:106-113.

20. Odigie, I.P., Ettarh, R.R. and Adigun, S.A. (2003). Chronic Administration of Aqueous Hibiscus sabdariffa Attenuates Hypertension and Reverses Cardiac Hypertrophy in 2k-IC Hypertrophy Rats. Journal of Ethnopharmacology. 8b (2-3): 181- 185.

21. Ogbuewu, I.P. (2008). Physiological Responses of Rabbits Fed Graded Levels of Neem (Azadirachta indica) Leaf Meal. M.Sc. Thesis, Federal University of Technology, Owerri.

22. Okasha, M.A.M., Abubakar, M.S. and Aya, B.I. (2008). Study of the effect of Aqueous Hibiscus sabdariffa Linn Seed Extract on serum Prolactin level of Lactating female albino rats, European Journal of Scientific Research. 22(4):575-583.

23. Ostadolova, I and Babicky, A. B. (2012). Periodization of the early postnatal development in the rat with particular attention to the weaning period. Physiological Research. 61 (suppl.1): S1-S7.

24. Ouedraogo Z.1., Heide, D.V., Beek, E.M.I.I., Swarts, H.J.M., Mattheij, J.A.M., Sawadogo, L. (2004). Effect of aqueous Acacia on milk production and prolactin release in the rat. Journal of Endocrinology. 182:257-266.

25. Patel, M.S. and Srinivasan, M., (2010). Metabolic programming due to alteration in nutrition in the immediate postnatal period. Journal of Nutrition. 140: 658-661.

26. Paul, H.A., Hallam, M.C. and Reimer, R.A. (2015). Milk Collection in the Rat Using Capillary Tubes and Estimation of Milk Fat Content by Creamatocrit. Journal of Visualized Experiments. 106: e53476, doi:10.3791/53476.

27. Sullivan, S., Schanler, R.J., Kim, J.H., Patel, A.L., Trawoger, R., Kiechl-Kohlendnfer, U., Chan, G.M., Blanco, C.L., Abrams, S., Cotton, C.M. (2010). An Exclusively Human Milk - based Diet is Associated with a Lower Rate of Necrotizing Enterocotitis than a Diet of Human Milk and Bovine Milk - Based Products. Journal of Pediatrics. 156: 562-567el.

28. Trease, G. E. and Evans, W. C. (2002). Pharmacognosy. $15^{\text {th }}$ ed. W. B. Saunders, Philadelphia. Pp 214-393.

29. Vasquez-Roman, S., Alonso-Diaz, C., Garcia-Lara, N.R., Escuder-Vieco, D. and Pallas-Alonso, C.R. (2014). Effect of freezing on the "creamatocrit" measurement of the lipid content of human donor milk. Annals of Pediatrics (Barc). 81: 185-188.

30. Wang, C. J., Wang, J. M., Lin, W. L., Chu, C.Y., Chou, F.P., and Tseng, T.H. (2000). Protective effect of Hibiscus anthocyanins against tert-butyl hydroperoxide-induced hepatic toxicity in rats. Food and Chemical Toxicology. 38(5): 411-416.

31. World Health Organization. (2013): Long-Term Effects of Breastfeeding: A Systematic Review; WHO: Geneva, Switzerland, 2013. Available online: http://www.who.int/maternal_child_adolescent/documents/breastfeeding_long_term_effects/en/ 